CZASOPISMO INŻYNIERII LĄDOWEJ, ŚRODOWISKA I ARCHITEKTURY JOURNAL OF CIVIL ENGINEERING, ENVIRONMENT AND ARCHITECTURE

JCEEA, t. XXXIII, z. 63 (4/16), październik-grudzień 2016, s. 133-140

\author{
Mariusz FILIPOWICZ ${ }^{1}$ \\ Estera PRZENZAK ${ }^{2}$
}

\title{
MODELOWANIE HYBRYDOWEJ INSTALACJI KOLEKTOROWEJ W UKŁADZIE CHŁODZENIA SŁONECZNEGO
}

\begin{abstract}
Przedstawiono znaczenie rozwoju technologii chłodzenia z wykorzystaniem energii promieniowania słonecznego. Systemy takie z reguły używają dodatkowego źródła ciepła pozwalającego osiągnąć temperaturę efektywnej pracy chłodziarki absorpcyjnej. W tym celu w wielu rozwiązaniach stosowane są dodatkowe źródła ciepła w postaci podgrzewaczy elektrycznych, gazowych i innych czyli używających energię nieodnawialną. W krajach południowych możliwa jest praca systemu chłodniczego wyłącznie w oparciu o energię odnawialną przy wykorzystaniu odpowiednio dużych zestawów kolektorów próżniowych. Jednakże w Polsce instalacje kolektorów słonecznych bazują najczęściej na kolektorach płaskich i nie posiadają tak dużej powierzchni. Dlatego przewidziano układ bazujący na kolektorach płaskich z dogrzewaniem czynnika roboczego w postaci koncentratora promieniowania słonecznego. W pracy przedstawiono opis stanowiska badawczego oraz wybrane wyniki badań pracy takiego hybrydowego układu. Wykonano modelowanie pracy układu hybrydowego w celu opisu temperatury na wyjściu z kolektora dla naturalnej zmienności godzinowej natężenia promieniowania słonecznego oraz dla kilku wybranych prędkości przepływu medium roboczego. Wykazano, że możliwy jest wystarczająco dokładny opis za pomocą uproszczonego modelu matematycznego koncentratora, jednakże wymagana jest znajomość parametrów technicznych koncentratora (m.in. sprawności odbiornika ciepła, sprawności koncentracji promieniowania i inne). W wielu przypadkach praktycznych dokładne określenie tych wielkości może być trudne. Dlatego przeprowadzono analizę czułości modelu na niepewności tych parametrów.
\end{abstract}

Słowa kluczowe: chłodzenie słoneczne, koncentracja promieniowania słonecznego, kolektory słoneczne, chłodziarka absorpcyjna, natężenie promieniowania słonecznego

\footnotetext{
${ }^{1}$ Autor do korespondencji/corresponding author: Mariusz Filipowicz, AGH Akademia GórniczoHutnicza, Wydział Energetyki i Paliw, al. Mickiewicza 30, 30-059 Kraków; tel. 126175192; filipow@agh.edu.pl

2 Estera Przenzak, AGH Akademia Górniczo-Hutnicza, Wydział Energetyki i Paliw, al. Mickiewicza 30, 30-059 Kraków; tel. 126173428; esterap@agh.edu.pl
} 


\section{Wprowadzenie}

W związku z podniesieniem komfortu życia coraz większego znaczenia nabiera kwestia chłodzenia pomieszczeń w upalne dni. Jednakże zwiększenie liczby systemów opartych na sprężarkach zasilanych energią elektryczną prowadzi do problemów związanych z przeciążeniem systemu elektroenergetycznego.

Rozwiązaniem może być stosowanie chłodzenia słonecznego, gdzie energia słoneczna dostępna jest wtedy kiedy istnieje największe zapotrzebowanie na chłód. Istnieje szereg rozwiązań stosowania chłodzenia absorpcyjnego. Przykładem może być instalacja opisana w [1], znajdująca się w budynku Instytutu Fraunhofera w Niemczech. Składa się z ponad czterystu kolektorów próżniowych o mocy cieplnej ok. $50 \mathrm{~kW}$ (na nasłonecznienia $1000 \mathrm{~W} / \mathrm{m}^{2}$ ). Instalacja jest zintegrowana z układem tzw. ,free cooling”. Zastosowano chłodziarkę absorpcyjną zasilaną gorącą wodą WFC-10 o mocy chłodniczej $35 \mathrm{~kW}$. Chłodzona jest powierzchnia o wielkości $270 \mathrm{~m}^{2}$. Wykazano m.in., że w tym przypadku dla wytworzenia jednego $\mathrm{kW}$ chłodu potrzeba ok. $4 \mathrm{~m}^{2}$ powierzchni kolektorów próżniowych. W wielu przypadkach energia otrzymywana $\mathrm{z}$ promieniowania słonecznego jest zbyt mała, powoduje to zbyt niską temperaturę czynnika roboczego. W celu otrzymania optymalnego poziomu temperatury stosuje się różne metody dogrzewania czynnika roboczego (np. kotły). Praca [2] podaje przykład uproszczonego modelu matematycznego układu z kolektorami słonecznymi, kotłem gazowym, chłodziarką absorpcyjną oraz elementami pomocniczymi instalacji. Wykazano m.in. warunki optymalizacji tego typu instalacji. W pracy [3] opisano prosty system z próżniowymi kolektorami słonecznymi i chłodziarką absorpcyjną o mocy $4.5 \mathrm{~kW}$. Średni współczynnik wydajności (COP) wynosił ok. 0.58 dla pracy w warunkach angielskich. Sposoby symulacji różnych rozwiązań słonecznych układów chłodniczych przedstawione są w [4], gdzie rozważono jedno, dwu i trzystopniowe chłodziarki absorpcyjne $\mathrm{LiBr}-\mathrm{H}_{2} \mathrm{O}$ w układzie z kolektorem słonecznym i dodatkowym źródłem ciepła. Jako kolektor analizowano: kolektory próżniowe, kolektory rynnowe z koncentratorem, liniowe koncentratory Fresnela, płaskie kolektory próżniowe. Wykazano, że najlepszą opcją dla szeregu warunków klimatycznych jest kombinacja płaskiego kolektora próżniowego i chłodziarek absorpcyjnych opartych na podwójnym efekcie. Przy użyciu takiego kolektora można wykorzystywać promieniowanie rozproszone.

Problemy z zasilaniem chłodziarek absorpcyjnych - z reguły wymagana temperatura pracy chłodziarki jest zbyt wysoka dla ciepła otrzymywanego z kolektorów słonecznych. Sprawność cyklu termodynamicznego i współczynnik COP jest zależny dość silnie od temperatury [5]. W wielu pracach opisujących zarówno analizę pracujących systemów jak i modelowych używane jest dodatkowe źródło ciepła, które ma wspomagać pracę niskotemperaturowego źródła jakimi są kolektory słoneczne. Dla przykładu w [6] zastosowano elektryczny ogrzewacz o mocy $10 \mathrm{~kW}$ dogrzewający olej do temperatury $185^{\circ} \mathrm{C}$ w zbiorniku o pojemności $1500 \mathrm{dm}^{3}$. Natomiast w [7] zastosowano kocioł gazowy, możliwe są jeszcze inne rozwiązania. 
W krajach o dużym nasłonecznieniu wymaganą temperaturę pracy można uzyskać przy pomocy kolektorów próżniowych o odpowiednio dużej powierzchni. W Polsce jednak one nie są zbyt popularne, przemawiają za tym koszty instalacji, pewne problemy eksploatacyjne. Natomiast powstaje coraz więcej instalacji z płaskimi kolektorami, które mają problemy z nadwyżka ciepła latem. Aby nie używać dogrzewania $\mathrm{z}$ wykorzystaniem nieodnawialnych źródeł energii zaproponowano dogrzewanie czynnika roboczego dedykowanym układem koncentratora promieniowania słonecznego opisanego w dalszej części artykułu.

\section{Opis procedury badawczej}

\subsection{Opis stanowiska badawczego}

Na Wydziale Energetyki i Paliw, AGH w Krakowie realizowane są badania hybrydowej instalacji kolektorów słonecznych z koncentratorem promieniowania słonecznego. Pełny schemat stanowiska pomiarowego przedstawiony został na rysunku 1. Łączna powierzchnia aktywna kolektorów wynosi $4,2 \mathrm{~m}^{2}$, natomiast powierzchnia koncentratora: $2,54 \mathrm{~m}^{2}$.

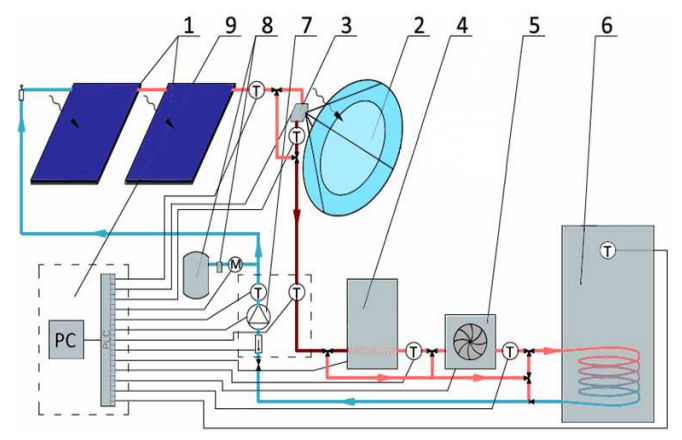

Rys.1. Schemat instalacji kolektorów słonecznych z koncentratorem promieniowania słonecznego do produkcji chłodu i zasilania ciepłej wody użytkowej [8]

Fig.1. Diagram of the solar system with the solar radiation concentrator for cooling and domestic heat water supply [8]

Czynnik roboczy (olej termiczny) jest pompowany do kolektorów słonecznych (1) za pomocą pompy obiegowej (7). Następnie wstępnie ogrzany czynnik trafia do odbiornika ciepła wysokotemperaturowego (3) umieszczonego w pobliżu ogniska koncentratora, gdzie jego temperatura rośnie. Powstałe ciepło ma być wykorzystywane do zasilania chłodziarki absorpcyjnej (4). Pozostałe ciepło gromadzi się w zbiorniku buforowym (6). Instalacja zabezpieczona jest przed nadmiernym wzrostem ciśnienia oraz przegrzaniem za pomocą naczynia wzbiorczego (8) i chłodnicy wentylatorowej (5). 


\subsection{Opis odbiornika skoncentrowanego promieniowania słonecznego}

Odbiornik ciepła wysokotemperaturowego pracujący w ognisku skupionych promieni stanowi jeden z najważniejszych elementów instalacji. Badania prowadzone są przy użyciu odbiornika płaskiego o powierzchni aktywnej $0,03 \mathrm{~m}^{2}$ wykonanego $\mathrm{z}$ aluminium $\mathrm{z}$ wyfrezowanym wewnątrz kanałem widocznym na rysunku 2.

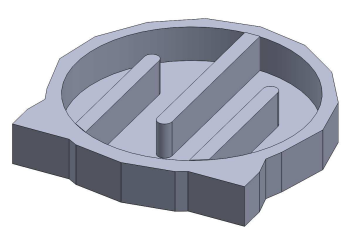

Rys.2. Płaski odbiornik ciepła wysokotemperaturowego

Fig.2. The flat high-temperature heat receiver

Równolegle z badaniami eksperymentalnymi prowadzone są symulacje komputerowe propagacji promieniowania w układzie optycznym koncentratora (metoda Ray Tracing Monte Carlo) oraz symulacje numeryczne przepływu czynnika wewnątrz odbiornika (metoda Computational Fluid Dynamics). Wyniki prac symulacyjnych zebrane zostały w $[9,10]$. W rezultacie wskazano, że najlepszym rozwiązaniem jest umiejscowienie odbiornika płaskiego w odległości $77 \mathrm{~cm}$ od powierzchni lustra przy jednoczesnym przepływie wynoszącym $0,6 \mathrm{~m} / \mathrm{s}$.

\section{Metodyka i wyniki badań}

W ramach badań opracowano model koncentratora promieniowania słonecznego, w którym skoncentrowane promieniowanie słoneczne konwertowane jest w odbiorniku na ciepło wysokotemperaturowe następnie ogrzewające olej termalny [11].

Temperatura medium roboczego $t_{o}$ dana jest następującym wyrażeniem :

$$
t_{o}=t_{i n}+\frac{q}{\dot{m} c_{p}}
$$

gdzie: Tin - temperatura medium na wejściu, q - ilość przekazanego ciepła do odbiornika, $\dot{m}$ - przepływ i $c_{p}$ - ciepło właściwe medium roboczego.

Natomiast moc cieplna $q$ dostarczana do płynu roboczego jest równa:

$$
q=A \cdot F_{R} \cdot\left[G_{T}-U_{L}\left(t-t_{a}\right)\right]
$$

gdzie: $A$ - powierzchnia odbiornika, $F_{R}$ - współczynnik odprowadzania ciepła, $G_{T}$ - natężenie skoncentrowanego promieniowania padającego na powierzchnię 
odbiornika, $U_{L}$ - sumaryczny współczynnik strat cieplnych odbiornika, $t$ - średnia temperatura medium wewnątrz odbiornika, $t_{a}$ - temperatura otoczenia.

Współczynnik odprowadzania ciepła $F_{R}$ dany jest wzorem:

$$
F_{R}=\frac{\dot{m} c_{p}}{A \cdot U_{L}}\left[1-\exp \left(-\frac{f_{P} U_{L} A}{\dot{m} c_{p}}\right)\right]
$$

gdzie $f_{p}$ - całkowita sprawność odbiornika.

W celu określenia natężenia promieniowania $G_{T}$ na powierzchni odbiornika posłużono się tzw. współczynnikiem koncentracji $C$ oraz natężeniem promieniowania bezpośredniego $G$ i uwzględniono nachylenie koncentratora względem kierunku padania promieniowania słonecznego na płaszczyznę koncentratora.

$$
G_{T}=C G \cos \psi_{z}
$$

Kąt $\psi_{z}$ pomiędzy normalną do płaszczyzny poziomej a płaszczyzny nachylenia koncentratora płaszczy wyznaczany był wg odpowiedniego algorytmu astronomicznego [11]. Należy tu zaznaczyć, że normalna do powierzchni koncentratora była jednoczenie kierunkiem padania promieni słonecznych - wskutek działania mechanizmu śledzenia położenia Słońca.

W praktyce dość trudno określić jest współczynnik koncentracji $C$, gdyż należy uwzględnić wiele czynników, m.in. współczynnik odbicia powierzchni odbijającej koncentratora, absorpcja w szkle, błędy ogniskowania, błędy śledzenia, refleksyjność powierzchni odbiornika. Wprawdzie poszczególne czynniki można wyznaczyć, jednakże wypadkowy wpływ tak wielu czynników prowadzić może do sporych niepewności.

Aby określić całkowity współczynnik strat cieplnych $U_{L}$ odbiornika należy przeanalizować dwa mechanizmy strat cieplnych: radiacyjne $h_{r}$ i konwekcyjne $h_{k}$ dane następującymi wyrażeniami:

$$
\begin{aligned}
& U_{L}=h_{r}+h_{k} \\
& h_{r}=\sigma \varepsilon_{p}\left(t_{m}^{2}+t_{s}^{2}\right)\left(t_{m}+t_{s}\right) \\
& h_{k}=5.7+3.8 \cdot v
\end{aligned}
$$

gdzie: $\sigma$ - stała Stefana-Boltzmana, $\varepsilon_{p}$ - emisyjność powierzchni odbiornika, $t_{m}$ - średnia temperatura medium roboczego $\mathrm{w}$ obszarze odbiornika, $t_{s}-\mathrm{tzw}$. zastępcza temperatura nieboskłonu, $v$ - prędkość wiatru.

Średnia temperatura medium $t_{m}$ dana jest jako $t_{m}=\left(t_{o}+{ }_{i n}\right) / 2$, czyli jest to średnia arytmetyczna temperatury medium na wlocie i wylocie. W algorytmach typu zaprezentowanych $\mathrm{w}$ [11] i bazujących na modelach płaskich, niskotemperaturo- 
wych kolektorów słonecznych, temperatura medium wyliczana jest w dwu krokach: najpierw określana jest moc cieplna przekazywana do odbiornika $q$, przy założeniu że współczynnik $U_{L}$ obliczany jest dla nienagrzanego medium w odbiorniku. W kolejnym kroku określana jest temperatura medium na wyjściu $t_{o}$, a dla niej temperatura $t_{m}$ i uaktualniony współczynnik strat cieplnych $U_{L}$. Jednakże dla skoncentrowanego promieniowania słonecznego przyjście temperatury promieniującej powierzchni jako $t_{m}$ nie jest poprawne, gdyż jak pokazały m.in. obliczenia [10] temperatura powierzchni odbiornika może być nawet kilkadziesiąt stopni wyższa (w zależności od przepływu medium) od średniej temperatury medium roboczego w odbiorniku.

\section{Analiza wyników}

Do opisu danych eksperymentalnych wykorzystano przykładowy pomiar wykonany 11.08.2015. Pomiar obejmował kilkugodzinną rejestrację parametrów pracy układu dla zmiennego zachmurzenia i zmiennego (ustawianego arbitralnie) przepływu medium roboczego. Wyniki przedstawione są na rysunku 3.

Na rysunku 3 prezentowana jest zmierzona temperatura medium roboczego przy przepływie oleju zmniejszanego ok. $0.5 \mathrm{l} / \mathrm{min}$ od wartości $7 \mathrm{l} / \mathrm{min}$ do $2 \mathrm{l} / \mathrm{min} \mathrm{z}$ krokiem $10 \mathrm{~min}$. Temperatura zewnętrzna wahała się $\mathrm{w}$ zakresie 26-32 ${ }^{\circ}$ C. Pomiar rozpoczął się ok. 9.30.

Otrzymano przybliżone wartości współczynnika strat cieplnych odbiornika $U_{L}=22.8 \mathrm{~W} /\left(\mathrm{m}^{2} \mathrm{~K}\right), \mathrm{z}$ tego na straty konwekcyjne przypada $17.1 \mathrm{~W} /\left(\mathrm{m}^{2} \mathrm{~K}\right)(\mathrm{dla}$ średniej prędkości wiatru podczas pomiaru) a na promieniowanie $5.7 \mathrm{~W} /\left(\mathrm{m}^{2} \mathrm{~K}\right)$. Współczynnik $F_{R}$ odprowadzania ciepła został oszacowany na 0.42 . Walidacja modelu została wykonana w celu określenia czułości modelu na dane wejściowe i zdolność opisu danych eksperymentalnych.

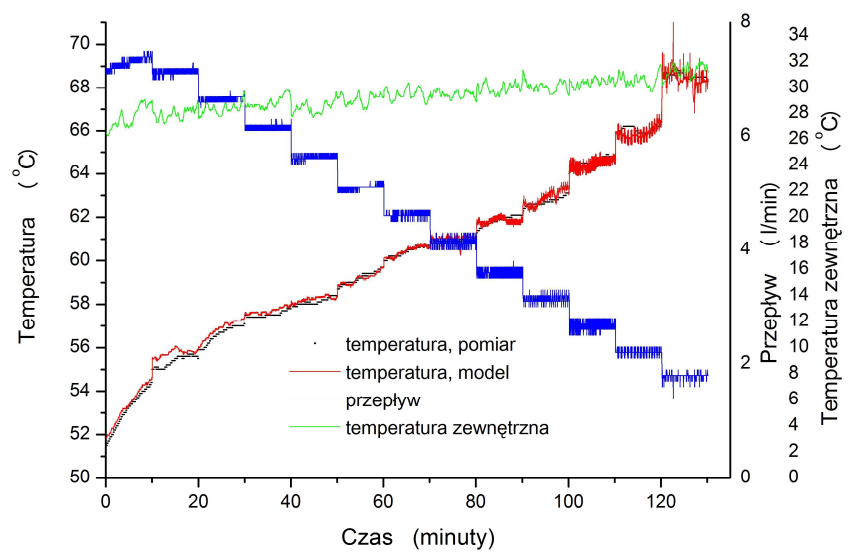

Rys.3. Opis zmian temperatury medium roboczego po przejściu przez koncentrator dla zmiennego natężenia przepływu

Fig.3. Description of the working medium temperature variation at the concentrator output for varied flow 
Problemem podczas analizy danych eksperymentalnych była możliwość określenia bezpośredniego natężenia promieniowania słonecznego na podstawie pomiaru całkowitego natężenia promieniowania słonecznego i zweryfikowania jej, poprzez model koncentratora promieniowania słonecznego z wynikami badań. Szereg instalacji słonecznych (m.in. opisane w [12]) wyposażonych jest tylko w pomiar całkowitego natężenia promieniowania i ze względów praktycznych (poza instalacjami badawczymi) rozbudowa układów pomiarowych może nie być uzasadniona ekonomicznie, natomiast jednak układ sterujący może z większą efektywnością prowadzić sterowanie pracą instalacji jeżeli będzie miał informacje o natężeniu bezpośredniego promieniowania słonecznego, zatem kompromisem może być uzyskiwanie tych informacji z odpowiednio zwalidowanego modelu.

\section{Wnioski}

Działanie układu koncentrującego promieniowanie słoneczne w celu zwiększenia temperatury medium roboczego przepływającego przez specjalny typ odbiornika można z dobrą dokładnością opisać za pomocą modelu analitycznego, który może być adoptowany do obliczeń wymagających szybkości (np. w analizie stanów dynamicznych układu). Za pomocą odpowiednich procedur minimalizacyjnych można określić wartości parametrów układu, przy których dane będą opisywane najlepiej. Jednakże dla tak prostego modelu pojawia się problem odpowiedniej interpretacji otrzymanych parametrów. Brak pomiarów bezpośredniego promieniowania słonecznego (najlepiej na płaszczyznę koncentratora) powoduje, że staje się praktycznie niemożliwe określenie współczynnika odprowadzania ciepła. Wpływ na to ma również niezbyt adekwatny opis temperatury powierzchni odbiornika - konieczne będzie tu wprowadzenie modyfikacji temperatury na podstawie modelowania CFD i pomiarów termograficznych.

\section{Literatura}

[1] Ahmed Hamza H. Ali, Peter Noeres, Clemens Pollerberg, Performance assessment of an integrated free cooling and solar powered single-effect lithium bromide-water absorption chiller, Solar Energy 82 (2008), pp. 1021-1030.

[2] J.V.C. Vargas, J.C. Ordonez, E. Dilay, J.A.R. Parise, Modeling, simulation and optimization of a solar collector driven water heating and absorption cooling plant, Solar Energy 83 (2009), pp. 1232-1244.

[3] Francis Agyenim, Ian Knight, Michael Rhodes, Design and experimental testing of the performance of an outdoor $\mathrm{LiBr} / \mathrm{H} 2 \mathrm{O}$ solar thermal absorption cooling system with a cold store, Solar Energy 84 (2010), pp. 735-744.

[4] Ali Shirazi, Robert A. Taylor, Stephen D. White, Graham L. Morrison, A systematic parametric study and feasibility assessment of solar-assisted single-effect, doubleeffect, and triple-effect absorption chillers for heating and cooling Applications, Energy Conversion and Management 114 (2016), pp. 258-277.

[5] Bożek E., Zdunek M., Nowoczesne systemy chłodnicze zasilane skoncentrowanym promieniowaniem słonecznym, Bezpieczeństwo energetyczne - rynki surowców i energii: energetyka w czasach politycznej niestabilności, 2015, s. 687-694. 
[6] M. Izquierdo, A. González-Gil, E. Palacios, Solar-powered single-and double-effect directly air-cooled $\mathrm{LiBr}-\mathrm{H} 2 \mathrm{O}$ absorption prototype built as a single unit, Applied Energy 130 (2014), pp. 7-19.

[7] Andrés Macía, Luis A. Bujedo, Teresa Magraner, César R. Chamorro, Influence parameters on the performance of an experimental solar-assisted ground-coupled absorption heat pump incooling operation, Energy and Buildings 66 (2013), pp. 282-288.

[8] Przenzak E., Filipowicz M., Hybrid solar receiver as a source of high-temperature medium for an absorption chiller supply, Experimental Fluid Mechanics 2015, s. 656-663.

[9] Bożek, E. , Filipowicz, M., Wykorzystanie techniki śledzenia promienia do modelowania wysokotemperaturowych układów helioenergetycznych. Czasopismo Inżynierii Lądowej, Środowiska i Architektury - Journal of Civil Engineering, Environment and Architecture, JCEEA, t. XXXII, z. 62 (2/15), 2015, s. 19-28, DOI:10.7862/rb.2015.32.

[10] Bożek E., Szubel M., The numerical model of the high temperature receiver of the concentrated solar radiation, SDEWES 2015, Conference on Sustainable Development of Energy, Water and Environment Systems, Dubrownik, (2015), s. 1-12.

[11] Włodzimierz Smolec, Fototermiczna konwersja energii słonecznej, Wydawnictwo Naukowe PWN, Warszawa 2000.

[12] J. Knaga, Modelowanie transferu energii elektrycznej i ciepła w małych, autonomicznych układach solarnych, Inżynieria Rolnicza 144(2013) T.2 (rozprawa habilitacyjna).

Praca wykonana $w$ ramach dziatalności statutowej WEiP, AGH

„Badania uwarunkowań zrównoważonego rozwoju energetycznego”

\section{MODELLING OF HYBRID COLLECTOR SOLAR COLING INSTALLATION}

\section{S u m m a r y}

The importance of developing solar cooling technologies was described in the paper. Described system mostly use additional heat source to achieve temperature sufficient for efficient operation of an absorption unit. In this aim, in many of the installation such auxiliary heat sources as: electric, gaseous, etc are applied. This heat source use non-renewable energy. In the countries of the south operation of the system using only renewable energy is possible - it require large areas of evacuated tube collectors. However, in Poland solar installations are mostly smaller and based of flat plate solar collectors. Therefore in this paper we consider system based on flate-plate collectors with heating up of working medium by a solar concentrator. Description of the experimental hybrid installation and selected results for variable medium flow are presented in the paper.

It was confirmed that it is possible create sufficiently accurate description of the installation by simplified mathematical model, but it requires knowledge of some technical parameters as: efficiency of the heat receiver, concentrating ratio and others. In many practical cases accurate determination of those parameters is difficult. Appropriate anylysis of sensitivity of those parameters were performed.

Keywords: solar cooling, solar radiation concentration, solar collectors, absorption chiller, solar radiation intensity

DOI:10.7862/rb.2016.256

Przestano do redakcji: $1.06 .2016 r$.

Przyjęto do druku: 20.12.2016 r. 